\title{
Transcranial Magnetic Stimulation of the Prefrontal Cortex in Awake Nonhuman Primates Evokes a Polysynaptic Neck Muscle Response That Reflects Oculomotor Activity at the Time of Stimulation
}

\author{
@Chao Gu (顾超) $)^{1,2,4}$ and $® B r i a n$ D. Corneil ${ }^{1,3,4}$ \\ ${ }^{1}$ The Brain and Mind Institute, Robarts Research Institute, London, Ontario N6A 5B7, Canada, and ${ }^{2}$ Graduate Program in Neuroscience, ${ }^{3}$ Department of \\ Physiology \& Pharmacology, and ${ }^{4}$ Department of Psychology, Western University, London, Ontario N6A 5B7, Canada
}

\begin{abstract}
Transcranial magnetic stimulation (TMS) has emerged as an important technique in cognitive neuroscience, permitting causal inferences about the contribution of a given brain area to behavior. Despite widespread use, exactly how TMS influences neural activity throughout an interconnected network, and how such influences ultimately change behavior, remain unclear. The oculomotor system of nonhuman primates (NHPs) offers a potential animal model to bridge this gap. Here, based on results suggesting that neck muscle activity provides a sensitive indicator of oculomotor activation, we show that single pulses of TMS over the frontal eye fields (FEFs) in awake NHPs evoked rapid (within $\sim 25 \mathrm{~ms}$ ) and fairly consistent ( $\sim 50-75 \%$ of all trials) expression of a contralateral head-turning synergy. This neck muscle response resembled that evoked by subsaccadic electrical microstimulation of the FEF. Systematic variation in TMS location revealed that this response could also be evoked from the dorsolateral prefrontal cortex (dIPFC). Combining TMS with an oculomotor task revealed state dependency, with TMS evoking larger neck muscle responses when the stimulated area was actively engaged. Together, these results advance the suitability of the NHP oculomotor system as an animal model for TMS. The polysynaptic neck muscle response evoked by TMS of the prefrontal cortex is a quantifiable trial-by-trial reflection of oculomotor activation, comparable to the monosynaptic motor-evoked potential evoked by TMS of primary motor cortex. Our results also speak to a role for both the FEF and dIPFC in head orienting, presumably via subcortical connections with the superior colliculus.
\end{abstract}

Key words: animal model; frontal cortex; frontal eye fields; oculomotor system; saccades; TMS

\section{Introduction}

Transcranial magnetic stimulation (TMS) has emerged as an important methodology in cognitive neuroscience (for review, see Hallett, 2007). While TMS can be combined with human neuroimaging (Siebner et al., 2009), an in-depth understanding of how TMS influences neural activity requires animal models (Mueller et al., 2014). Studies in anesthetized rodents (Ji et al., 1998), felines (Moliadze et al., 2003), and nonhuman primates (NHPs; Salinas et al., 2013) have described frequency-dependent and intensity-dependent effects of TMS on neural and hemodynamic activity. Generalizing these anesthetized results to humans is limited since the behavioral effects of TMS likely reflect its influence

\footnotetext{
Received July 16, 2014; revised Sept. 8, 2014; accepted Sept. 30, 2014.

Author contributions: C.G. and B.D.C. designed research; C.G. performed research; C.G. and B.D.C. analyzed data; C.G. and B.D.C. wrote the paper.

This work was supported by operating grants from the Canadian Institutes of Health Research (MOP \#93796, MOP \#123247). We thank Dr. S. Cushing for surgical implantation of the neck EMG electrodes, K. Green for expert technical and surgical assistance, K. Barker for technical support, and S. Dash and S. Lehmann for comments on an earlier version of the manuscript.

The authors declare no competing financial interests.

Correspondence should be addressed to Brian D. Corneil, The Brain and Mind Institute, Robarts Research Institute, London, 0N N6A 5B7, Canada. E-mail: bcorneil@uwo.ca.

DOI:10.1523/JNEUROSCI.2907-14.2014

Copyright $\odot 2014$ the authors $\quad 0270-6474 / 14 / 3314803-13 \$ 15.00 / 0$
}

on both the stimulated area and other interconnected regions, particularly when TMS is applied outside of primary sensory or motor areas. A number of groups (Gerits et al., 2011; ValeroCabre et al., 2012) have suggested that the NHP oculomotor system offers a better model for understanding the effects of TMS on brain and behavior. Seminal work by these groups established the feasibility of this animal model by showing that TMS of the frontal eye fields (FEFs), an area involved in saccade control (for review, see Johnston and Everling, 2011), influenced saccadic reaction time (SRT). While encouraging, the reported effects required comparison to the SRT on control trials (which can be quite variable), necessitating numerous trials and hindering systematic exploration of how different TMS parameters (e.g., location, intensity) influence oculomotor behavior.

A series of results from our laboratory suggest that neck muscle activity provides an alternative, and perhaps a more sensitive, indicator of oculomotor activity (Corneil and Munoz, 2014). In NHPs, electrical microstimulation of the FEF evokes robust recruitment of a contralateral head-turning synergy (Elsley et al., 2007), which persists even if stimulation current is lower than that required to evoke saccades (Corneil et al., 2010). Stimulation of the nearby supplementary eye fields (SEFs) evokes the same neck muscle response (Chapman et al., 2012), with the magni- 
tude of recruitment scaling with endogenous activity at the time of stimulation (Chapman and Corneil, 2014). Such state dependency is also a hallmark of TMS (for review, see Silvanto et al., 2008). TMS of the FEF in humans also evokes state-dependent recruitment of a contralateral head-turning synergy (Goonetilleke et al., 2011).

The first goal of this paper is to examine whether TMS of the FEF in NHPs evokes the same neck muscle response as microstimulation and, if so, to quantify how such an evoked response changes with manipulations of TMS location and intensity. Our second goal is to examine whether any evoked neck muscle response changes when delivered during a behavioral task. To facilitate comparison, we used the same task as in humans (Goonetilleke et al., 2011), delivering TMS of the FEF before leftward and rightward memory-guided saccades. Our results indicate that TMS throughout a large extent of the prefrontal cortex (PFC) evokes the same neck muscle response as evoked by microstimulation, with the magnitude of recruitment depending on the location and intensity of TMS, and on endogenous activity at the time of stimulation.

Preliminary results have been presented in abstract form $(\mathrm{Gu}$ et al., 2013).

\section{Materials and Methods}

Three male macaque monkeys (two Macaca mulatta, monkeys $s p$ and $z n$, and one Macaca fascicularis, monkey al) weighing $\sim 13,12$, and $9 \mathrm{~kg}$, respectively, performed in these experiments. All training, surgical, and experimental procedures were approved by the Animal Use Subcommittee of the University of Western Ontario Council on Animal Care, and were conducted in accordance with the Canadian Council on Animal Care policy on the use of laboratory animals, which conforms to the guidelines laid down by the National Institutes of Health regarding the care and use of animals for experimental procedures. The NHPs' health and weight were monitored daily.

Surgical preparation. Each NHP underwent two surgeries. In the first surgery, a titanium head post for head restraint and a grid of receptacles that served as markers (10 $\mathrm{mm}$ spacing) were embedded within an acrylic implant. A mixture of titanium and ceramic screws were used to secure the acrylic, with ceramic screws placed in the vicinity of where TMS would be delivered. The grid of receptacles was placed directly on the left (monkeys $s p$ and $a l$ ) or the right (monkey $z n$ ) anterior quarter of the skull, covering cortical areas anterior to the central sulcus. The rationale of the grid-and-receptacle technique is based on neuronavigation, but our method takes advantage of embedding the receptacles permanently in the acrylic to offer a simple means of reproducing TMS location from day to day. Each receptacle was filled with a $2 \mathrm{~g} / \mathrm{l}$ copper(II) sulfate solution (monkeys sp [nine receptacles] and $z n$ [six receptacles]) or threaded to receive rods filled with the same solution (monkey al [10 receptacles]; Fig. 1A). This solution was highly visible during an anatomical MRI scan conducted for each monkey. From this scan, we constructed a 3-D rendering of the location, and referenced receptacle locations to underlying cortical landmarks, such as the central, arcuate, and principal sulci (Fig. 1A, right subplots). In monkey al, the grid of receptacles was designed to also mesh with a mating plastic mold fit to the bottom of the TMS coil, enabling us to stabilize the TMS coil within the dental acrylic. In all NHPs, the thickness of the acrylic was kept as thin as possible over the intended locations of TMS $(\sim 7-10 \mathrm{~mm}$, which was the height of the receptacles). NHPs have quite thick muscles of mastication, and from scans of monkeys without implants, we measured the thickness of the muscles and skin above the skull over the frontal cortex to range between 6 and $8 \mathrm{~mm}$ in a $9.6 \mathrm{~kg}$ male Macaca mulatta, and $8-10 \mathrm{~mm}$ in a $8.5 \mathrm{~kg}$ male Macaca fascicularis. Thus, the distance from the TMS coil to the cortical surface is about the same as it would be if TMS were to be applied directly to the scalp. Further, due to the skull's low conductivity, the electric fields induced in the brain will be very similar regardless of whether TMS is applied directly to the scalp or to acrylic, providing the thickness of these segments is the same.
A
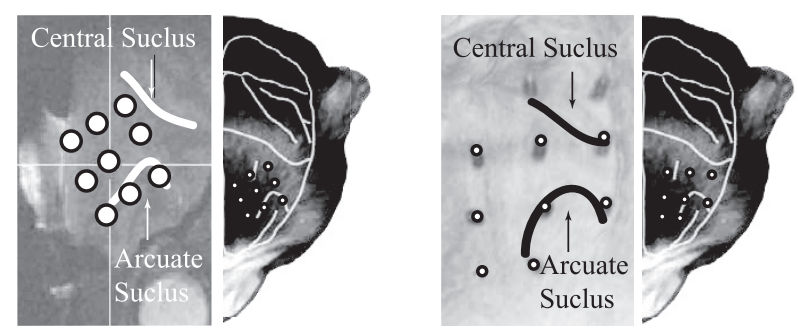

B

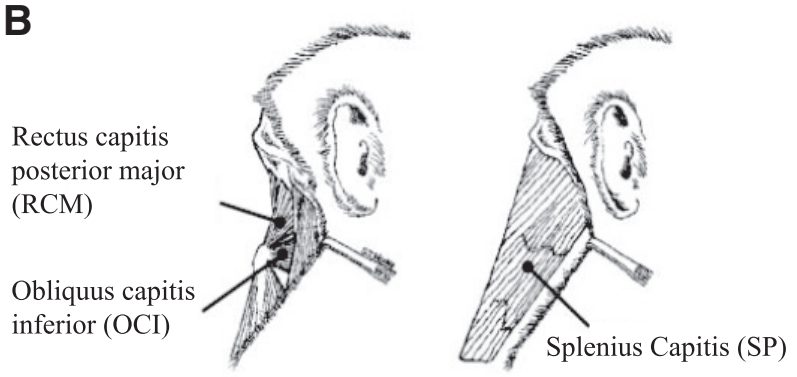

C

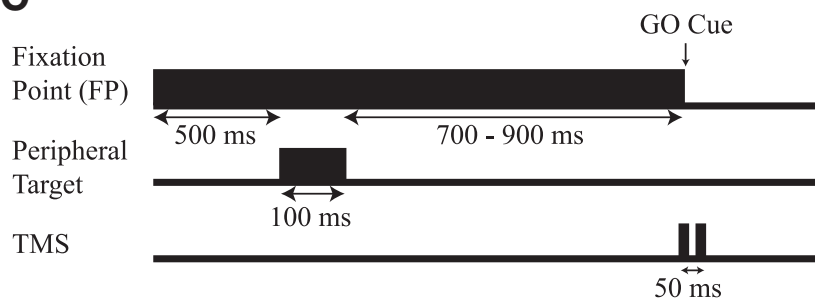

Figure 1. A, The locations of the fiducial markers for both monkeys sp and al overlaid on their anatomical MRI scans, with the central and arcuate sulcus highlighted (left subplots), and a representative head of a monkey with the estimated locations of the fiducial makers (right subplots). $\boldsymbol{B}$, Schematic line drawings of the muscles of interest, which were implanted bilaterally. All three of these muscles contribute to horizontal head turns to the ipsilateral side. C, The memory-guided saccade paradigm. The FP remained illuminated prior, during, and after a peripheral target was flashed $20^{\circ}$ left or right. Two TMS pulses $(20 \mathrm{~Hz}, 50 \mathrm{~ms}$ apart) were delivered on one-third of all trials, concurrently with FP offset, which also served as the $G 0$ cue for the monkey to look at the remembered location of the target.

In the second surgery, chronically indwelling bipolar hook electromyography (EMG) electrodes were implanted bilaterally into three dorsal neck muscles responsible for horizontal head turning (for surgical details, see Elsley et al., 2007). The implanted muscles included two deep suboccipital muscles: obliquus capitis inferior (OCI) and rectus capitis posterior major (RCM), and the more superficial splenius capitis (SP) muscle (Fig. 1B). These muscles contribute to horizontal head turns to the side of the muscle (Corneil et al., 2001) and are robustly recruited by extracellular stimulation of the FEF (Elsley et al., 2007) and the SEF (Chapman et al., 2012). Leads from these electrodes were tunneled subcutaneously up to the skull and connected to a connector embedded within the acrylic.

TMS. Biphasic pulses of TMS were applied over the acrylic implant using a MagStim Rapid Transcranial Magnetic Stimulator with a figureeight coil designed for peripheral nerve stimulation $(25 \mathrm{~mm}$ inner coil radius; MagStim). This specific coil has been previously used by other TMS studies with NHPs (Amaya et al., 2010; Gerits et al., 2011; ValeroCabre et al., 2012). The TMS coil was held in position by a customized clamp anchored to the head post. The center of the TMS coil was placed directly on top of the receptacles or dental acrylic for monkeys $s p$ and $z n$, or set by positioning a plastic mold on the bottom of the coil into the grid receptacles for monkey al. The coil was placed surface normal to the acrylic and rotated $45^{\circ}$ clockwise from anterior-posterior directional 
current flow, to induce a posterior-medial to anterior-lateral direction current flow.

Behavioral paradigms. The NHPs were placed in a customized primate chair (Crist Instruments). All experiments were conducted with the head restrained in a dark, sound-attenuated room. NHPs were placed $0.6 \mathrm{~m}$ away from an array of red LEDs.

We delivered TMS in two experimental contexts. In the first context, single pulses of TMS were delivered while NHPs simply fixated at a fixation point (FP). Neck muscle responses were measured while TMS coil location over the frontal cortex was varied systematically (the mapping experiment) or while the level of TMS output was varied (the intensity experiment). Our rationale for requiring the NHPs to fixate during TMS was because tonic neck muscle activity varies with eye-in-head position (Stuphorn et al., 1999; Corneil et al., 2002). In the mapping experiment, the intensity of TMS was set to the lowest levels capable of reliably recruiting contralateral neck muscle activity [45, 40, and $35 \%$ of maximum stimulation output (MSO) for monkeys $s p, z n$, and $a l$, respectively]. The coil was moved systematically to different locations in 5 or 10 $\mathrm{mm}$ steps, similar to a recent TMS study of NHP primary motor cortex (M1) study (Amaya et al., 2010). At each location on a given day, we delivered single pulses of TMS 25 times, triggering TMS manually while the monkey fixated at a central FP. For a given mapping session conducted within a single day, TMS was delivered to $\leq 20$ different locations, with the order of locations randomly selected at the beginning of the day. A total of 10 complete mapping sessions were collected for both monkeys $s p$ and $a l$; a total of 3 mapping sessions were collected for monkey $z n$.

Based on the results of the mapping experiment, the TMS location with the largest evoked contralateral neck muscle response was identified for monkeys $s p$ and $a l$. Using these locations, we examined the effect of systematic variations of the different levels of stimulator output (intensity experiment). First, we examined contralateral neck muscle recruitment, varying the intensity of TMS in 5\% increments from $5 \%$ below to $15 \%$ above the TMS intensity level used in the mapping experiment (40-60\% and 30-50\% MSO for monkeys sp and al respectively). All other experimental details were the same as in the mapping experiment. A total of 10 sessions were conducted for both NHPs, with the order of intensity settings within a single day selected randomly. Second, based on previous reports that TMS of M1 can suppress the activity of antagonist muscles at lower stimulation levels than that required to excite agonist muscles (Kimiskidis et al., 2005; Werhahn et al., 2007), we collected an additional series of 10 sessions with stimulator output varying in 5\% increments from $5 \%$ below to $25 \%$ below stimulator output in the mapping experiment (20-35\% MSO and 15-30\% MSO for monkeys sp and al respectively). During this experiment, the NHPs looked at a FP positioned $20^{\circ}$ horizontally ipsilateral to the side of TMS coil, which increased the background EMG activity on the antagonist muscles of interest; all other experimental details were the same as in the mapping experiment.

In the second context, we delivered TMS in conjunction with a behavioral task. To facilitate comparisons, NHPs performed a memory-guided saccade task (Fig. 1C), with the timing of TMS matching that performed in previous human studies (Wipfli et al., 2001; Goonetilleke et al., 2011). To achieve a liquid reward, the monkeys first had to look at a central FP within a $6^{\circ}$ radius window, maintaining central fixation before $(500 \mathrm{~ms})$, during (100 ms), and after (700-900 ms, varied randomly among four equally spaced intervals) presentation of a peripheral visual target. The peripheral target was flashed $20^{\circ}$ to the left or right of the FP. The NHP was then allowed to saccade to the remembered location of the peripheral target within $800 \mathrm{~ms}$ after the disappearance of the FP (i.e., the disappearance of the FP served as the GO cue), within an $8^{\circ}$ radius window. The peripheral target reappeared $100 \mathrm{~ms}$ after the monkey entered the window, and the monkey maintained fixation in the target window for an additional $300 \mathrm{~ms}$. Two pulses of TMS $(20 \mathrm{~Hz}, 50 \mathrm{~ms}$ apart $)$ were delivered on one-third of all trials, with the first pulse of TMS coinciding with FP disappearance (Fig. 1C). Window size remained the same on trials with or without TMS. All trial conditions (left or right cue, with or without TMS) were pseudorandomly interleaved within a session of $\geq 240$ successful trials. Within such a session, the NHP had to complete a block of 30 trials (5 or 10 trials with or without TMS in each direction) before moving to the next block. The intensity of TMS was set at 20, 25, and $25 \%$ for monkeys $a l, s p$, and $z n$, respectively; these intensities were close to the lowest stimulator intensity that evoked an antagonist muscle response from the intensity experiment.

Across different sessions, the location of TMS was varied among three distinct groups. In the first group of sites, the PFC group, TMS was applied to sites on or anterior to the arcuate sulcus, where TMS in the mapping experiment evoked a contralateral head-turning synergy (three, four, and one different sites in monkeys $a l, s p$, and $z n$ respectively; similar EMG and behavioral results were obtained at all locations, and hence the data were pooled together in the results). This group of sites allowed us to test whether neck muscle responses evoked by TMS varied with an oculomotor task, as predicted by state dependency. In the second group of sites, the auditory control group, TMS was delivered $5 \mathrm{~cm}$ above the scalp (monkeys al and $s p$ ) directly over the PFC sites to control for the acoustic noise of TMS pulses. In the third group of sites, the brain control group, TMS was applied to a site posterior to the arcuate sulcus (monkeys $a l$ and $s p$ ), where TMS was not able to evoke a contralateral head-turning synergy in the mapping experiment. This group serves to additionally control for any other sensations associated with TMS, and also tested for spatial specificity of any effects seen with the PFC group. Importantly, the site tested in monkey al was the location from where TMS evoked a different profile of neck muscle activity, which may have arisen from TMS to M1 (see Results). We observed no difference in the neck EMG or behavioral results obtained between the auditory control group and brain control group, and hence have pooled the results from these two control groups together in the results.

Data acquisition. Eye-in-head position was tracked with an eyetracking system (ETL-200, iScan) at $120 \mathrm{~Hz}$. The processing of the EMG signals commenced at the headstage (Plexon), which was plugged into the EMG connector embedded within the acrylic implant. The headstage performed differential amplification of the EMG signals $(20 \times$ gain) and filtering (bandwidth, $20 \mathrm{~Hz}$ to $17 \mathrm{kHz}$ ). A flexible ribbon cable linked the headstage to the Plexon preamplifier, which contained a signal processing board customized for EMG recording $(50 \times$ gain bandwidth, $100 \mathrm{~Hz}$ to $4 \mathrm{kHz}$ ). All analog signals were digitized at $10 \mathrm{kHz}$.

Off-line analyses were conducted with customized Matlab (Mathworks) programs. Further details regarding analysis windows are given in the Results. EMG signals were rectified and downsized into $1 \mathrm{~ms}$ bins, as previously described (Elsley et al., 2007). For the mapping and intensity experiments, trials with baseline EMG activity $>3$ SEs away from the mean from the pooled baseline were rejected. For the memory-guided saccade paradigm, a customized graphical user interface permitted trialby-trial inspection. Eye position data were passed through a Butterworth filter, and a program automatically detected the beginning and end of saccades using a velocity threshold of $30 \%$ s. Trials with SRTs $<80 \mathrm{~ms}$ relative to the GO cue were rejected for being anticipatory, whereas trials with SRTs $>500$ ms relative to the GO cue were rejected for presumed inattention. All trials with blinks were rejected for monkey al; while trials with blinks were accepted for both monkeys $s p$ and $z n$ (see Results). Blinks had very distinct characteristic eye traces, with both horizontal and vertical eye position changing instantaneously by $>30^{\circ}$. No SRTs were derived from trials with blinks in monkeys $s p$ and $z n$.

\section{Results}

All three NHPs acclimatized to delivery of TMS within the first day of application and showed no signs of discomfort (note that all NHPs were trained on oculomotor tasks before introduction of TMS). This allowed us to collect a substantial dataset from two monkeys ( $s p$ and $a l$ ), and a smaller dataset from a third monkey $(z n)$. Overall there was no qualitative difference between the three synergistic muscles we recorded from, and hence we report the results from bilateral OCI for monkeys $a l$ and $z n$, and bilateral SP for monkey $s p$ (bilateral OCI or RCM recordings were not available from monkey $s p$ due to electrode failure). An ipsilateral or contralateral neck muscle is defined as any muscle that turned the head toward or away from the stimulated cortex, respectively. In the first set of experiments, we studied the effects of TMS while 
the NHPs simply maintained stable fixation. We collected a total of 10 mapping sessions from monkeys $s p$ and $a l$, and 3 sessions from monkey $z n$. From these mapping sessions, we identified the location evoking the largest neck muscle response, and used this location to study the effects of manipulating stimulator output on both agonist (contralateral) neck muscle recruitment and antagonist (ipsilateral) neck muscle inhibition (20 sessions total for both monkey $s p$ and $a l$ ). In the second set of experiments, across all three monkeys, we collected a total of 110 sessions consisting of $\geq 240$ trials each in the memory-guided saccade paradigm: 73 sessions were the PFC group, 19 sessions were the auditory control group, and 18 sessions were brain control group. Collectively, this dataset is an order of magnitude greater than that collected by previous groups (Gerits et al., 2011; Valero-Cabre et al., 2012), further establishing the suitability of this animal model.

\section{Single pulse of TMS evokes contralateral head-turning synergy} Despite head restraint, TMS applied to the frontal cortex over the arcuate sulcus in all three monkeys reliably increased the activity of contralateral neck muscles and/or decreased the activity of ipsilateral neck muscles (Fig. 2; to account for difference between the muscles across the three animals, the EMG data were normalized to the mean baseline EMG activity $50 \mathrm{~ms}$ before TMS). This evoked response began $\sim 20$ ms after the TMS pulse, and persisted for $\sim 30 \mathrm{~ms}$ (see shaded regions). Neck muscle activity then either returned to prestimulation levels or rebounded above the prestimulation levels of activity on the ipsilateral muscles (Fig. 2, $A, C$ ). In this figure, we have purposely retained the stimulation artifact on the EMG traces (lighter portion of lines) to show that TMS at this intensity does not extend into the response window (shaded regions; the artifact in monkey al was negligible). The EMG responses evoked by TMS evolved simultaneously on ipsilateral and contralateral neck muscles when both responses were present, but the decrease in ipsilateral neck muscle activity tended to be more reliable. To determine whether TMS evoked a significant response when averaged across all $\sim 25$ trials, we used the 50 ms interval preceding TMS to define a $99 \%$ confidence interval (CI) for baseline activity for each session. For the examples shown in Figure 2, the activities of contralateral neck muscles and of ipsilateral neck muscles within the response window of $20-50 \mathrm{~ms}$ after TMS for all three monkeys were significantly greater and lower than the $99 \% \mathrm{CI}$, respectively. Overall, the synergy and timing of the neck muscle responses evoked by TMS resembled that evoked by intracortical microstimulation of FEF (Elsley et

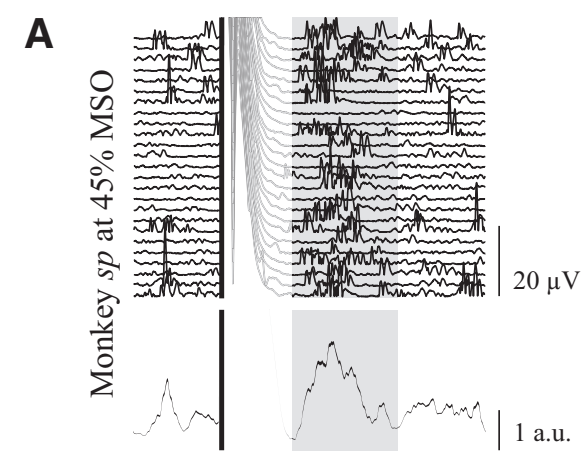

Ipsilateral Head Turner Muscle
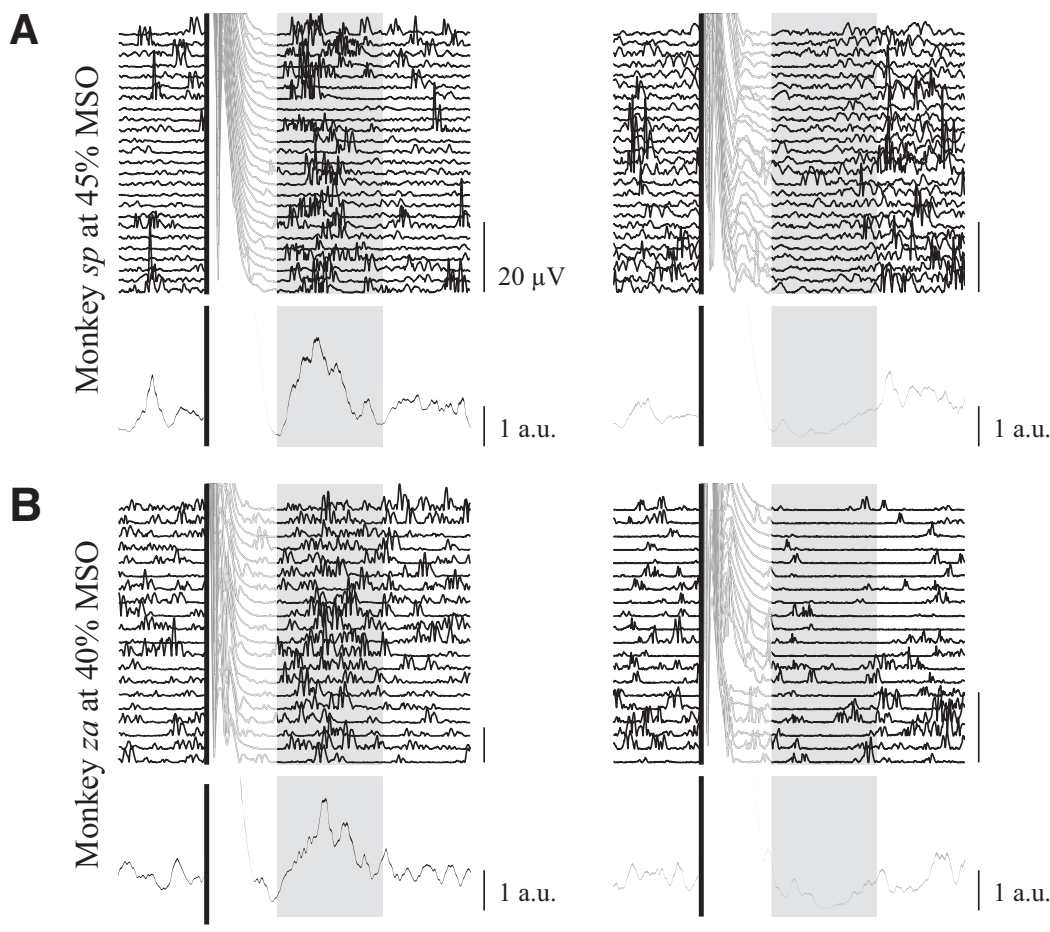

Figure 2. Representative examples from monkey $\operatorname{sp}(\boldsymbol{A})$, monkey $z n(\boldsymbol{B})$, and monkey al $(\boldsymbol{C})$ of the contralateral head-turning synergy evoked by single pulses of TMS over the superior arm of the arcuate. Rectified EMG activity aligned to TMS onset (solid black line) is shown for $\sim 25$ trials for contralateral and ipsilateral neck muscles (left and right columns respectively, the last trial is the muscles, respectively), which is normalized to the baseline EMG activity averaged from the $50 \mathrm{~ms}$ before TMS onset. In all monkeys, evoked a simultaneous increase or decrease in activity for contralateral or ipsilateral neck muscles $\sim 20-50$ ms after TMS (shaded box). TMS evoked a substantial artifact in monkeys sp and $z n$, and is shown as recorded in the individual traces in the lighter portions of the lines. Note that this artifact did not contaminate the response window. Scale bar for mean traces show the average baseline activity $50 \mathrm{~ms}$ before TMS.

al., 2007). Importantly, single-pulse TMS to the frontal cortex never evoked a saccadic eye movement, which is consistent with previous reports delivering TMS-FEF in humans (Müri et al., 1991; Wessel and Kömpf, 1991) and NHPs (Valero-Cabre et al., 2012). The ability of low-frequency forms of stimulation to evoke neck muscle responses without saccades likely reflects differences in the premotor properties of saccadic versus cephalomotor circuits (Corneil and Munoz, 2014), as electrical stimulation frequencies $<\sim 50 \mathrm{~Hz}$ are incapable of recruiting the brainstem saccadic burst generator (Tehovnik and Lee, 1993; Cavanaugh and Wurtz, 2004). Furthermore, we did not observe any tendency for the evoked response to adapt with repeated TMS application. 
A

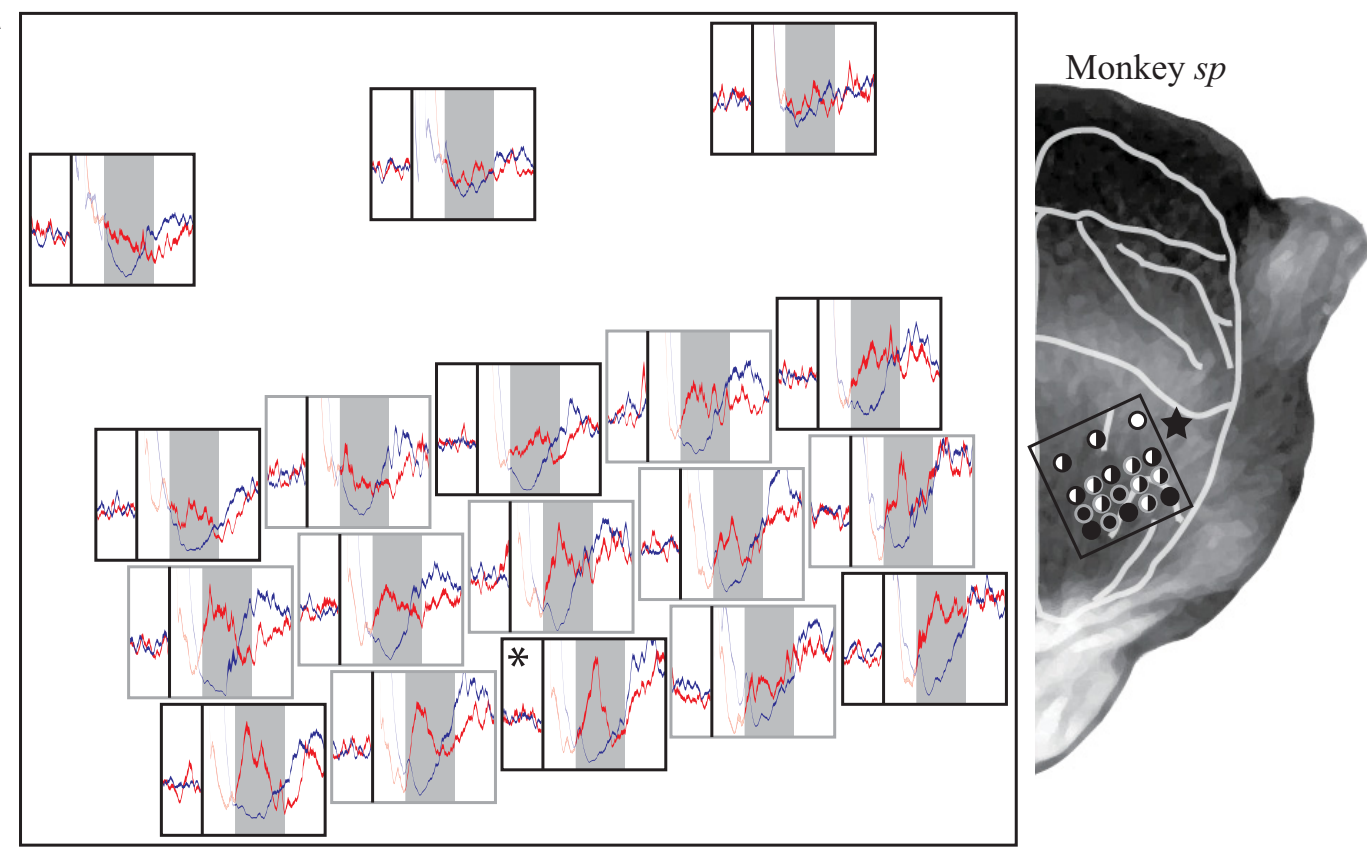

B

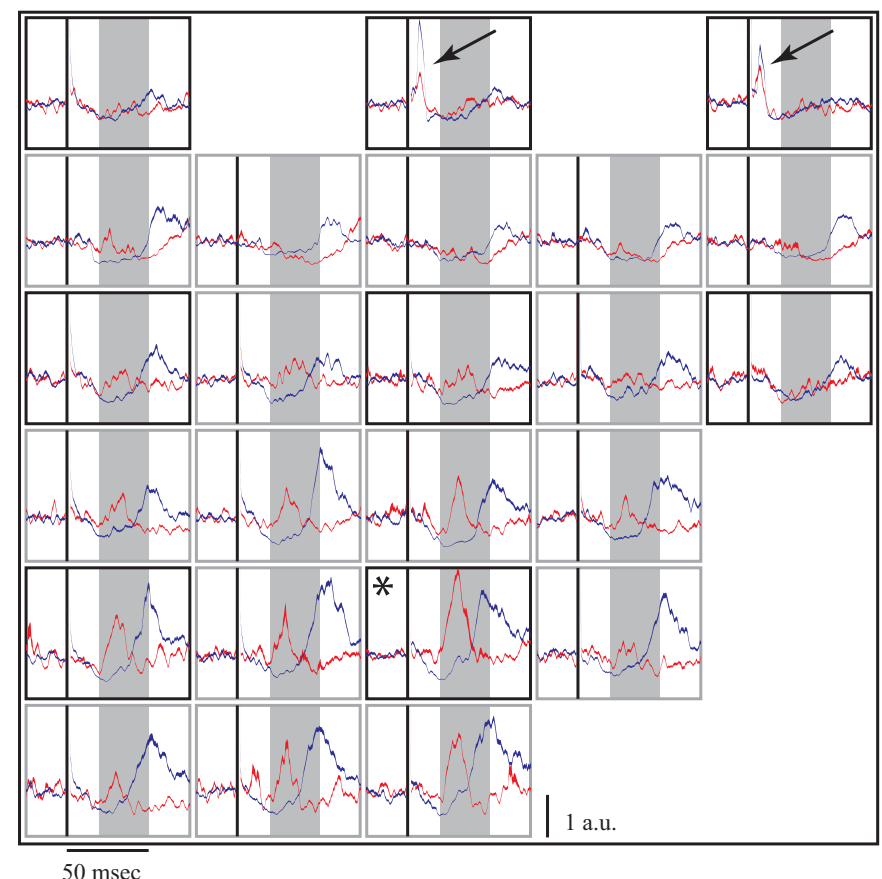

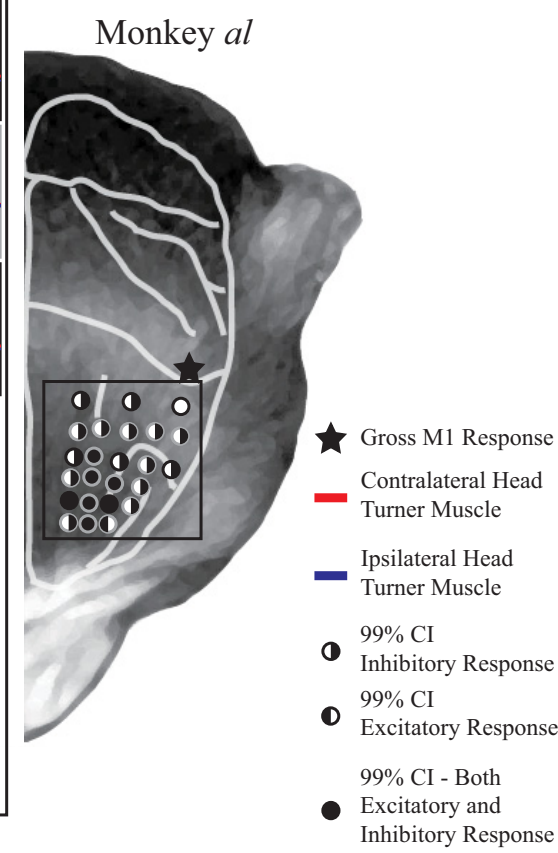

Figure 3. Results of the mapping experiment for monkey sp ( $\boldsymbol{A}$ ) and monkey al (B). Left, Each subplot shows the mean \pm SE of contralateral (red) and ipsilateral (blue) neck muscle activity aligned to TMS (black line), normalized to baseline activity at each site; shaded boxes show the response window, as in Figure 2. Right, The depicted sites represent approximate locations of markers projected onto a representation of a monkey's head for both monkeys $s p$ and $a l$. The asterisks in the left panel mark the location associated with the largest contralateral neck muscle response. Black arrows in $\boldsymbol{B}$ show locations from where TMS evoked a distinct profile of bilateral cocontraction in monkey al. Right, The filling of the circles indicates responses that went above or below the $99 \%$ Cls calculated from the baseline activity for contralateral and ipsilateral muscles, respectively (see legend). Black stars mark the locations from where a gross twitch from the contralateral hand could be evoked with TMS.

\section{TMS selectively evokes a contralateral head-turning synergy over PFC}

We sought to determine how the contralateral head-turning response evoked by TMS changed with systematic changes in TMS location. In all three monkeys, we moved the TMS coil based on the grid provided by the markers embedded in the acrylic, allowing us to map the evoked neck muscle response with a $5 \mathrm{~mm}$ resolution. As shown in Figure 3 for monkeys $s p$ and $a l$, TMS applied progressively more anterior evoked larger excitation in contralateral neck muscles and more prominent inhibition on ipsilateral neck muscles. Thus, over a wide expansion of the frontal cortex, anterior to and including the arcuate sulcus, TMS evoked a contralateral head-turning synergy. In both monkeys $s p$ and $a l$, the locations evoking the largest increases in contralateral neck muscles resided over the superior arm of the arcuate sulcus (Fig. 3, left, asterisks; these two sites were shown in Fig. 2). At 
both of these sites, on a trial-by-trial basis, TMS evoked an excitatory contralateral neck muscle response (wherein the average activity within a $10 \mathrm{~ms}$ window slid from 20 to $50 \mathrm{~ms}$ after TMS was $>3$ SEs above the baseline activity within that trial) on $56 \%$ (141 significant responses out of 249 trials; average response latency, $24 \mathrm{~ms}$ ) and $75 \%$ (185 significant responses out of 247 trials; average response latency, $23 \mathrm{~ms}$ ) of all trials for monkeys $s p$ and $a l$, respectively.

From the maps shown in Figure 3, it is clear that movements of the coil in the order of $0.5-1.0 \mathrm{~cm}$ could provoke distinct profiles of neck muscle activity. In both NHPs, the magnitude of the contralateral neck muscle response decreased substantially as the TMS coil was moved either posterior and/or lateral of the location associated with the peak response. Such findings are consistent with the topography of the FEF, where larger movements are evoked more medially (Bruce and Goldberg, 1985; Elsley et al., 2007), and with the changes in evoked oculomotor or hand muscle responses with 0.5 or 1 $\mathrm{cm}$ movements of the location of the TMS coil in NHPs (Amaya et al., 2010; Gerits et al., 2011; Valero-Cabre et al., 2012). To assess how well our grid of receptacles standardized TMS coil location, we also assessed the day-to-day repeatability of the evoked responses from a given location (recall the maps in Fig. 3 were constructed by pooling data collected over $10 \mathrm{~d}$ ). To do this, we first calculated the magnitude of any significant contralateral neck muscle response (averaged within a session of $\sim 25$ trials), and then rank-ordered all such magnitudes from smallest to largest. Using these ranks, we then calculated the sum of all ranked differences for the location associated with the largest response, and compared this real sum to a bootstrapped distribution obtained by shuffling ranks 10,000 times. For both NHPs, the real sum of ranked differences lay below the $99 \%$ CI of the bootstrapped distribution, meaning that magnitudes recorded when revisiting a location were more similar than the magnitudes recorded when visiting different nearby locations.

Although the increase and decrease on the contralateral and ipsilateral neck muscle activity appeared to evolve simultaneously, there were some subtle differences in these responses when TMS was applied over or slightly posterior to the arcuate sulcus. TMS at these locations occasionally evoked prominent decreases in ipsilateral neck muscle activity without changing contralateral neck muscle activity (Fig. $3 A$, second row for monkey sp; Fig. 3B, second and third row for monkey al ). Accordingly, the areas over which a reliable decrease in ipsilateral neck muscle activity could be evoked were larger than the areas over which an increase in contralateral neck muscle activity could be evoked (Fig. 3).

\section{TMS near the central sulcus evokes a distinct pattern of} bilateral neck muscle cocontraction

In monkeys sp and al, TMS 10\% higher than the intensity used for the mapping experiment evoked an observable twitch on the contralateral hand when applied near the central sulcus (Fig. 3, right, stars; higher intensities may have been required since the acrylic tended to be thicker for more posterior locations). We presumed that these locations corresponded to the hand representation of M1, which have been previously reported in monkey TMS studies (Edgley et al., 1997; Amaya et al., 2010; Valero-Cabre et al., 2012). During our mapping experiment in monkey $a l$, we encountered locations slightly anterior and medial to the hand representation where TMS evoked a distinct profile of bilateral neck muscle recruitment (Fig. 3B, left, top row, arrows). Such locations lay posterior to locations from where contralateral neck muscle activity could not be evoked. This bilateral response began within $\sim 5 \mathrm{~ms}$ of the TMS pulse and lasted only $\sim 5 \mathrm{~ms}$ in total. Following this response, both contralateral and ipsilateral neck muscles exhibited a brief period of reduced activity for another $\sim 20 \mathrm{~ms}$ before returning to baseline. The timing and profile of this response are consistent with TMS evoking activity along a different, perhaps corticospinal or corticoreticulospinal, pathway than that evoked when TMS is applied to more anterior locations (see Discussion). The longer stimulation artifacts in both monkeys $s p$ and $z n$ obscured our ability to replicate this observation. Note however in monkey $s p$ that TMS at the most posterior locations (Fig. 3A, left panel, top row) did produce a hint of bilateral suppression that differed from the neck muscle responses evoked at more anterior locations; such bilateral suppression may correspond to the brief period of reduced activity observed in monkey al after bilateral cocontraction.

\section{TMS intensity modulates the magnitude of the contralateral} head-turning synergy

Having established the TMS locations that recruit a contralateral head-turning synergy, we now examine the influence of TMS intensity. For both monkeys $s p$ and $a l$, we modulated stimulator output while delivering TMS to the sites with the largest and most reliable response (Fig. 3, asterisks). Increasing TMS intensity 
A

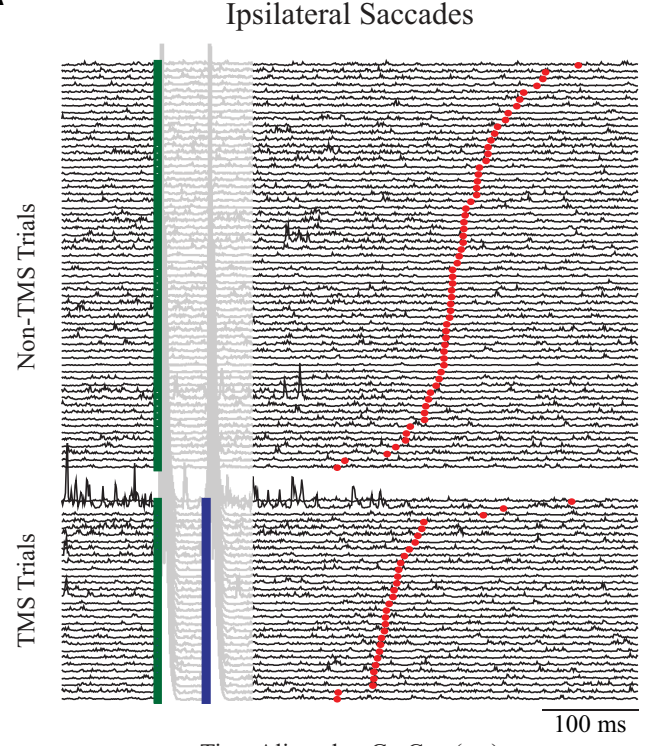

Time Aligned to Go Cue (ms)

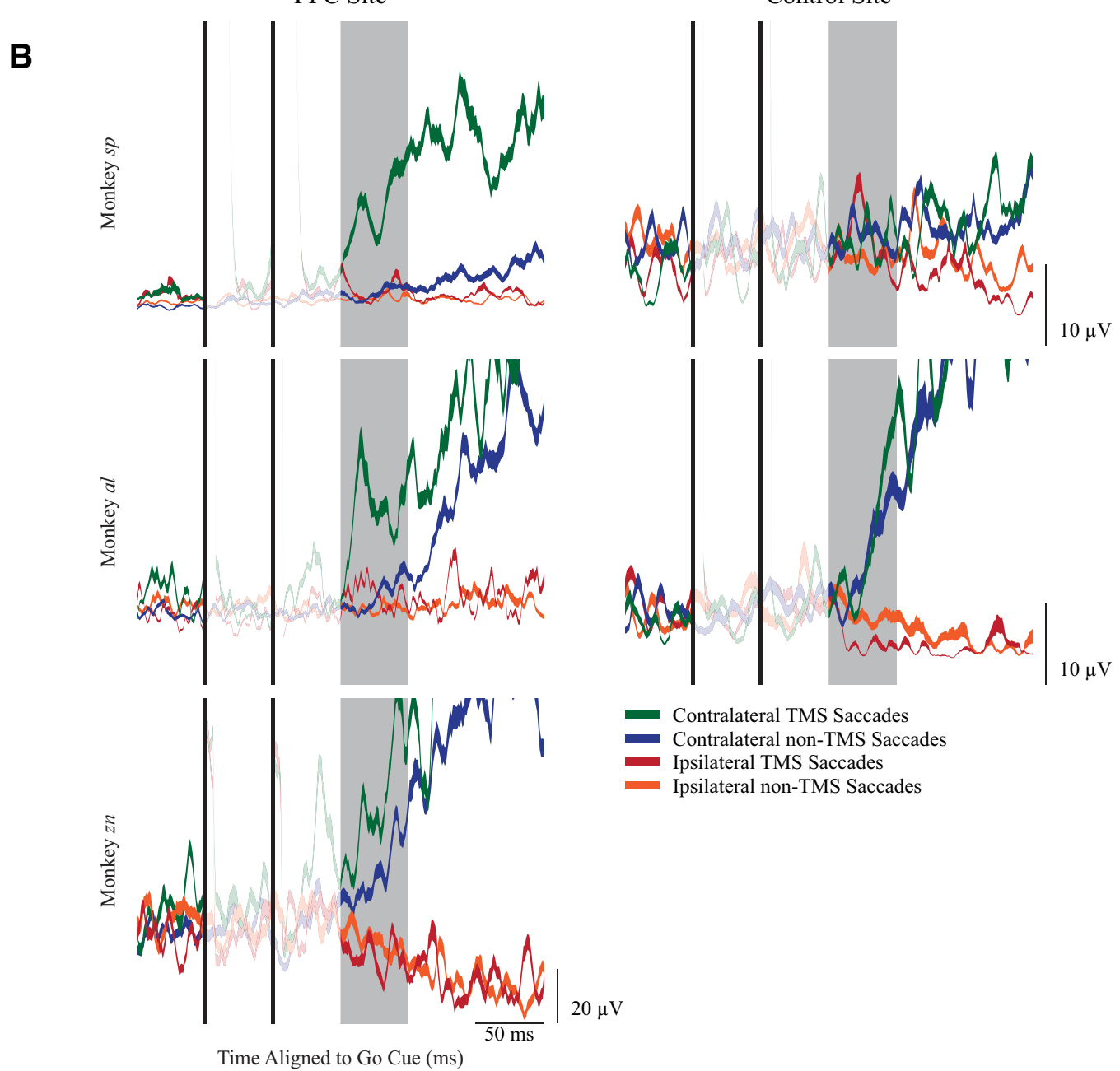

Figure 5. State-dependent recruitment of contralateral turning neck muscles in the memory-guided saccade task. $\boldsymbol{A}$, Neck EMG activity from individual trials from one session of the memoryguided saccade task from monkey sp, aligned to the $\mathrm{GO}$ cue (green square). Trials are segregated by saccade direction, and whether TMS was delivered (bottom; the second of the two TMS pulses is shown in the blue square). Trials are ordered by SRT (red circle). $\boldsymbol{B}$, Representative examples of mean \pm SE. EMG activity from contralateral turning muscles from single sessions, with TMS delivered either over the PFC (left column, same session for monkey sp as shown in $\boldsymbol{A}$ ) or to a control site for monkeys sp and al. All data aligned to the $\mathrm{G} 0$ cue; the shaded box shows the response window for quantification, $100-150 \mathrm{~ms}$ after the $\mathrm{GO}$ cue. 
raised the magnitude of the contralateral neck muscle recruitment, but did not noticeably decrease the time of response onset (Fig. 4A). Previous studies of human TMS to M1 have shown that TMS can inhibit antagonist muscle activity at lower levels than that required to excite agonist muscle activity (Kimiskidis et al., 2005; Werhahn et al., 2007). We therefore separately determined the lowest TMS intensity capable of suppressing the activity of ipsilateral neck muscles. For this experiment, monkeys fixated $20^{\circ}$ ipsilateral to the side of TMS, increasing background activity of the muscles of interest. In both monkeys $s p$ and $a l$, a substantially lower TMS intensity could inhibit ipsilateral neck muscle activity, compared with that required to evoke excitation of contralateral neck muscle (Fig. 4B). Based on these results, we determined that MSO settings of 25 and $15 \%$ were capable of inhibiting ipsilateral neck muscle activity for monkeys $s p$ and $a l$, respectively. We used this level as references for the active motor threshold in the next experiment.

\section{TMS over PFC evoked a state-dependent neck muscle response during a memory-guided saccade task}

We now turn to the effects of TMS to the frontal cortex during an oculomotor task. A central tenet of TMS is state dependency, wherein the effects of TMS reflect the endogenous activity in an area at the time of stimulation. To test state dependency, we occasionally delivered low-intensity TMS just before the monkeys generated contralateral and ipsilateral memory-guided saccades, relative to the side of the TMS coil. Much of the PFC, including the FEF, is more active before contralateral memoryguided saccades (Bruce and Goldberg, 1985; Funahashi et al., 1990). Hence TMS should evoke larger neck muscle responses when delivered before contralateral versus ipsilateral memoryguided saccades. For this experiment, we delivered two pulses of low-intensity TMS $(20 \mathrm{~Hz})$ aligned to the GO cue, with levels at or above the active motor threshold determined above (25\% MSO for monkeys sp and $z n, 20 \%$ MSO for monkey al).

Figure $5 \mathrm{~A}$ shows contralateral neck muscle activity for individual trials from a single session for monkey $s p$ where the TMS coil was placed over the PFC, segregated by saccade direction and whether TMS was delivered or not. All trials are aligned to the GO cue and further sorted based on saccadic reaction time (red circle). Even in the absence of TMS, contralateral neck muscle activity increased just before contralateral saccades and remained tonically elevated, and decreased just before ipsilateral saccades and remained tonically suppressed. Such phasic and tonic coupling of neck muscle activity with saccades and eccentric eye positions have been previously described in NHPs (Stuphorn et al., 1999; Corneil et al., 2002). However, TMS evoked a further increase in contralateral neck muscle activity only when delivered before contralateral saccades (Fig. $5 \mathrm{~A}$, lower-right plot); note the activity $100-150 \mathrm{~ms}$ after the GO cue that is not present before contralateral saccades in the absence of TMS, nor before ipsilateral saccades whether TMS was delivered or not. Thus, as predicted by state dependency, TMS only increased contralateral neck muscle activity when delivered to the PFC that is presumably more active before contralateral memory-guided saccades.

Representative session averages from all three monkeys when TMS was applied over the PFC or control sites are shown in Figure $5 B$ (using the PFC session shown in Fig. 5A for monkey $s p$ ). To quantify state dependency, we first calculated the average EMG activity 100-150 ms after the GO cue for all four conditions in a session, conservatively excluding any trials with SRTs $<175$ $\mathrm{ms}$ to reduce the confound of phasic changes in neck EMG associated with short-latency saccades. For the representative examples for all three monkeys, the greatest level of EMG activity in the window of interest occurred on trials where TMS of the PFC preceded contralateral saccades. Consistent with state dependency, such evoked activity was a function of both saccade direction and TMS of the PFC. No such state dependency was observed when TMS was applied to control sites (Fig. 5B, right plots).

Across our sessions, we first compared the effects of the presence or absence of TMS before contralateral saccades. For sessions involving TMS of the PFC, neck muscle activity was consistently larger 100-150 ms after GO cue before contralateral saccades on TMS versus non-TMS trials (Fig. 6A; 18\% of all sessions were significant, Bonferroni corrected; overall $17 \%$ median increase, paired $t$ test, $t_{(72)}=6.1, p<1 \times 10^{-7}$ ); note how the data in Figure $6 \mathrm{~A}$ clusters above the line of unity. In contrast, when TMS was applied to control sites either posterior to the arcuate (brain control sites) or into the air (auditory control sites), we observed much more modest increases in neck EMG before contralateral saccades when TMS was applied (Fig. 6B;3\% of all sessions were significant, Bonferroni corrected; overall $6 \%$ median increase, paired $t$ test, $\left.t_{(36)}=3.1, p<0.01\right)$. Although significant, we suspect that much of this effect reflects the overall decrease in SRT when TMS is applied at control sites (see below). Importantly, some of the sites visited for the brain control group were the sites from where bilateral neck EMG could be evoked in the mapping study; TMS at such sites did not evoke a statedependent effect, emphasizing the spatial specificity of the effect of TMS of the PFC on neck EMG during this oculomotor task. Finally, there was no effect of TMS before ipsilateral saccades regardless of whether TMS was applied to the PFC or to control 


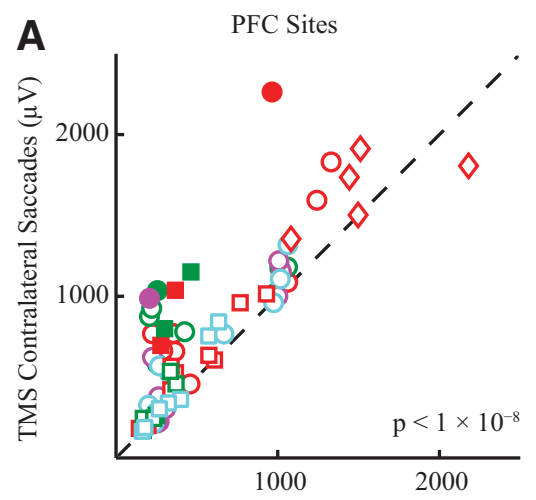

TMS Ipsilateral Saccades $(\mu \mathrm{V})$

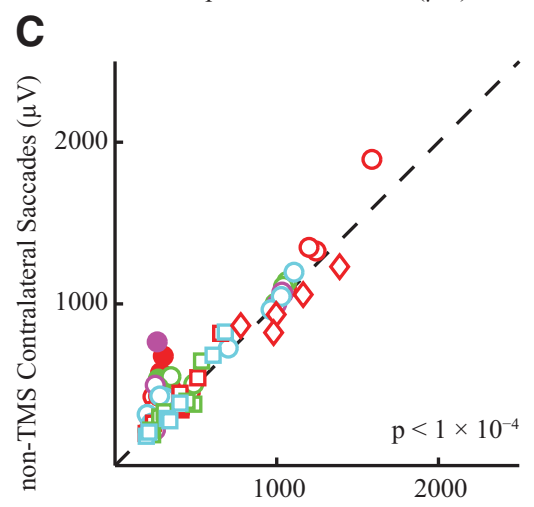

non-TMS Ipsilateral Saccades $(\mu \mathrm{V})$

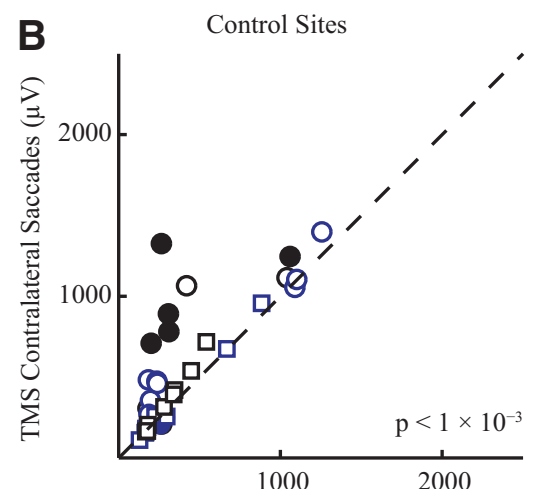

TMS Ipsilateral Saccades $(\mu \mathrm{V})$

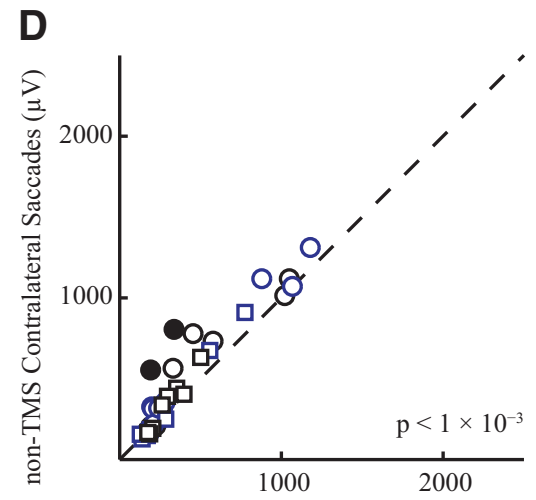

non-TMS Ipsilateral Saccades $(\mu \mathrm{V})$

Figure 7. Quantification of effect of saccade direction on EMG response evoked by TMS. Same general format as Figure $6 . \boldsymbol{A}, \boldsymbol{B}$, Comparison of effect of TMS before contralateral or ipsilateral saccades when TMS was either delivered to the $\operatorname{PFC}(\boldsymbol{A})$ or not $(\boldsymbol{B})$. $\boldsymbol{C}$, $D$, Comparison of the effect of saccade direction in the absence of TMS, for sessions where TMS was applied to the PFC $(\boldsymbol{C})$ or not $(\boldsymbol{D})$.

sites (data not shown; TMS of the PFC: $7 \%$ of all sessions were significant, overall $1 \%$ median decrease, paired $t$ test, $t_{(72)}=1.0$, $p=0.32$; TMS control: $7 \%$ of all sessions were significant, overall $1 \%$ median decrease, paired $t$ test, $\left.t_{(36)}=0.2, p=0.85\right)$.

Next, we compared the effects of TMS delivered before contralateral versus ipsilateral saccades. Figure 7 plots the mean EMG activity of contralateral versus ipsilateral TMS saccade trials from each session for both PFC sites $(A)$ and control sites $(B)$. For the PFC sites, data lay well above the line of unity, meaning that there were consistently greater levels of neck EMG following TMS before contralateral versus ipsilateral saccades ( $11 \%$ of all sessions were significant, Bonferroni corrected; overall $24 \%$ median increase, paired $t$ test, $t_{(72)}=6.7, p<1 \times 10^{-8}$ ). We also observed greater activity before contralateral versus ipsilateral saccades when TMS was delivered to control sites (19\% of all sessions were significant, Bonferroni corrected; overall 13\% median increase, paired $t$ test, $t_{(36)}=3.6, p<1 \times 10^{-3}$ ), however this result was mainly due to the preparation of contralateral versus ipsilateral saccades, since similar results were observed on non-TMS trials for both PFC and control sites (Fig. 7C,D; TMS of the PFC: 7\% of all sessions were significant, Bonferroni corrected; overall $6 \%$ median increase, paired $t$ test, $t_{(72)}=4.2, p<1 \times 10^{-4}$; TMS control: $8 \%$ of all sessions were significant, Bonferroni corrected; overall $11 \%$ median increase, paired $t$ test, $t_{(36)}=4.1, p<1 \times$ $\left.10^{-3}\right)$. Thus, while the simple preparation for a contralateral saccade increases neck EMG activity in the window of interest, neck EMG is further increased if TMS is delivered over the PFC.

For monkey sp, TMS of the PFC often induced blinks (59\% of all TMS of the PFC trials, regardless of saccade direction), obscuring our ability to extract SRT from such trials. Neck EMG activity from blink trials from monkey $s p$ were included in the above analyses provided the saccade after the blink attained the target. To ensure that blinks did not confound our results from this monkey, we compared neck EMG activity before contralateral saccades in the window of interest on TMS trials with and without blinks, and found no differences (two-way $t$ test, $\left.t_{(1178)}=-0.18, p=0.85\right)$. For monkey al, blinks rarely occurred on TMS of the PFC trials $(<1 \%)$, and hence we simply discarded blink trials as errors.

\section{TMS selectively decreased contralateral saccadic reaction times}

Next we examined whether TMS influenced SRT. In humans, TMS of the FEF in this task decreased contralateral but not ipsilateral SRT (Wipfli et al., 2001; Goonetilleke et al., 2011). However, unlike the neck EMG results, we did not find any systematic effect of TMS compared with controls when we analyzed SRT on a session-by-session basis. We then pooled SRTs across sessions to determine whether TMS influenced SRT, similar to a previous study of TMS of the FEF in NHPs (Gerits et al., 2011).

We pooled all trials without blinks for monkeys sp (Fig. 8A) and al (Fig. 8B), and segregated the data by saccade direction, presence or absence of TMS, and whether TMS was applied to the PFC sites or the control sites. In both monkeys, TMS shortened SRT bilaterally regardless of whether it was applied to the PFC or to control sites, although such decreases on contralateral trials tended to be slightly larger for TMS of the PFC (monkey sp: contralateral SRTs decreased by 62 and 44 $\mathrm{ms}$ for PFC and control sites, respectively; ipsilateral SRTs decreased by 14 and 19 ms for PFC and control sites; monkey al: contralateral SRTs decreased by 18 and $11 \mathrm{~ms}$ for PFC and control sites, respectively; ipsilateral SRTs decreased by 40 and $37 \mathrm{~ms}$ for PFC and control sites). To analyze this dataset, we performed separate two-way ANOVAs on SRT for contralateral or ipsilateral saccade trials for each monkey for a total of four different ANOVAs, using the application (TMS vs no-TMS trials) and location (PFC vs control) of TMS as factors. For both monkeys sp and al, this revealed a significant interaction between TMS application and location for contralateral saccade trials $\left(F_{(1,4183)}=22.3, p<\right.$ $1 \times 10^{-5}$, and $F_{(1,7596)}=8.7, p<0.01$, for monkey $s p$ and $a l$ respectively) but no significant interaction between TMS and location for ipsilateral saccade trials $\left(F_{(1,4262)}=2.0, p=0.15\right.$, and $F_{(1,7633)}=3.5, p=0.06$, respectively). This confirms that TMS application interacted with TMS location for contralateral but not ipsilateral saccades in a fashion resembling that reported in humans (Wipfli et al., 2001; Goonetilleke et al., 2011).

\section{Sessions with larger neck EMG responses tend to feature larger decreases in SRT}

Finally, we investigated whether there was any relationship between the magnitude of neck EMG evoked by TMS and changes in saccade latency. Our previous TMS work in humans revealed a weak correlation between greater evoked neck EMG with larger 
SRT decreases (Goonetilleke et al., 2011), and trial-by-trial activity in the superior colliculus (SC) correlates to both neck EMG and SRT (Rezvani and Corneil, 2008). Because of the prevalence of blinking with monkey $s p$, we were only able to use the data from monkey al. A direct trial-by-trial correlation of evoked neck EMG did not reveal any systematic relationship, perhaps because of the substantial trial-by-trial and session-bysession variance in both EMG and SRT. However, we did see a relationship across sessions between the size of the evoked neck EMG response and the decrease in SRT; sessions with larger neck EMG responses on contralateral TMS trials tended to be those sessions where TMS evoked larger decreases in contralateral SRT. To do this analysis, we rank-ordered the mean decrease in contralateral SRT across all sessions, and compared this to the ranked-ordered mean increase in neck EMG for contralateral trials. We then summed up the absolute difference between the two ranks for each session, and compared this difference to 1000 randomly shuffled pairs of ranking. The actual sum difference of our ranking compared with the randomly shuffled pairs was significantly smaller $(p<0.05)$ when TMS was delivered to PFC sites, but not significant ( $p=0.24$ ) when TMS was delivered to control sites.

\section{Discussion}

Our results indicate that TMS in NHPs over a large swath of PFC evokes rapid and brief recruitment of a contralateral headturning synergy. Such evoked neck EMG responses provide a quantifiable metric that is comparable to motor-evoked potentials (MEPs) evoked by TMS of M1, enabling systematic explorations of TMS location, intensity, and behavioral task. This work advances the use of the oculomotor system of awake, behaving NHPs as an animal model for understanding the effects of TMS. Our results also suggest that the dorsolateral PFC (dlPFC) contributes to head orienting.

\section{The contralateral head-turning synergy as a signature of evoked oculomotor activity}

The timing and patterning of neck muscle recruitment following TMS matches well with that evoked by intracortical microstimulation of the FEF (Elsley et al., 2007). The comparatively longer latency for TMS ( $\sim 25 \mathrm{~ms}$ for TMS vs $17 \mathrm{~ms}$ for microstimulation) could reflect the increase in response latencies from weaker stimulation intensities (Hadjidimitrakis et al., 2007; Corneil et al., 2010). Based on the short response latencies, both forms of stimulation appear to elicit neck muscle responses via feedforward recruitment along a polysynaptic pathway that likely includes the SC, from where microstimulation evokes the same patterning of neck EMG 3-4 ms earlier than the FEF (Corneil et al., 2002). Our previous work has forwarded a mechanism
Monkey $s p$

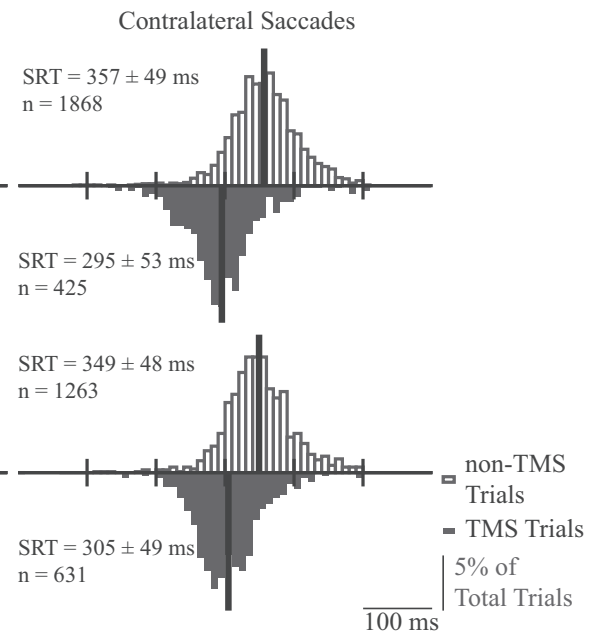

Monkey al
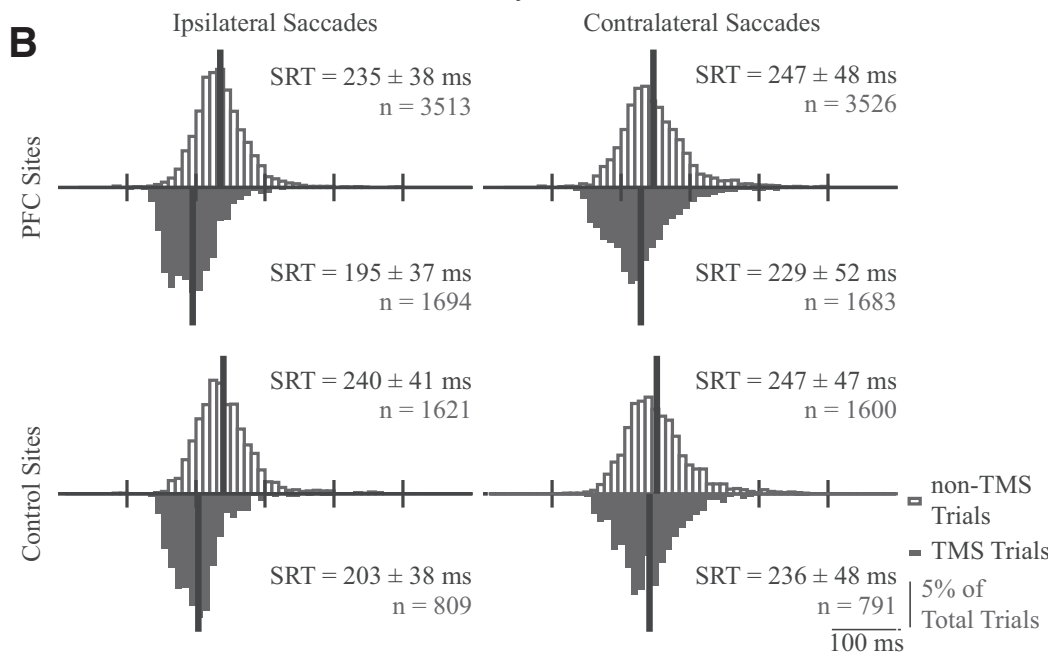

Figure 8. $\boldsymbol{A}, \boldsymbol{B}$, Frequency histograms for SRTs for monkeys sp ( $\boldsymbol{A})$ and al $(\boldsymbol{B})$ in the memory-guided saccade task (8 ms bins). (iptograms are plotted separately based on direction relative to the side of stimulation (ipsilateral or contralateral saccades in left (downward black histograms) or not (upward hollow histograms). Black vertical lines indicate histogram means. Statistics for each plot give the mean SRT $\pm S D$ and the number of observations.

for why the cephalomotor component of orienting provides a more sensitive indicator than saccades for small perturbations of the oculomotor system (for review, see Corneil and Munoz, 2014).

The timing and patterning of neck EMG evoked by TMS constrains plausible mechanisms. For example, TMS evoked the contralateral head-turning synergy only when delivered over and anterior of the arcuate sulcus, which is inconsistent with spatially nonspecific mechanisms, such as acoustic startle. Loud sounds ( 115-130 dB, compared with 75-85 dB for TMS in humans; Dhamne et al., 2014) can evoke neck EMG in humans but, unlike our results, such neck EMG consists of bilateral neck muscle recruitment that begins $\sim 60 \mathrm{~ms}$ after the click (Oude Nijhuis et al., 2007) and rapidly adapts (Brown et al., 1991). Startle arising from TMS, regardless of whether TMS is applied on or over the head, can perturb saccade trajectory if applied within $\sim 50 \mathrm{~ms}$ of saccade onset (Xu-Wilson et al., 2011). Such results differ from our observations regarding the dependencies of evoked neck EMG on TMS location; note as well that the minimum interval between the second of two TMS pulses and the onset of memory- 
guided saccades in our experiment was $125 \mathrm{~ms}$. Finally, acoustic startle can reduce SRTs (Siegmund et al., 2001; Castellote et al., 2007). While this may explain why memory-guided SRTs were reduced bilaterally regardless of where TMS was applied in our experiment, large increases in contralateral neck EMG only occurred when TMS was applied over the PFC before contralateral saccade trials, which is consistent with TMS summing with endogenous activity associated with the upcoming contralateral saccade.

When passed during a task, the neural activity induced by TMS is thought to contribute noise that disrupts subsequent behavior (Pascual-Leone et al., 2000; Miniussi et al., 2013). Such a mechanism was invoked to explain the changes in antisaccade SRTs following single-pulse TMS of the FEF in NHPs (ValeroCabre et al., 2012). While TMS may well be perturbing activity throughout the oculomotor system before a saccade, our results demonstrate that TMS first produces a pulse of excitation proportional to endogenous activity that propagates through a polysynaptic pathway. Consistent with this, short-duration electrical stimulation of the SEF evokes the largest neck muscle responses in conditions where it also produces the greatest disruption in saccade behavior (Chapman and Corneil, 2014). Together, these results hint at the complexity in the response of the oculomotor network following very short duration perturbation that can play out over tens if not hundreds of milliseconds.

\section{A broader role for the dIPFC in orienting the head}

Given the area from which TMS evoked the contralateral headturning synergy, we suspect that the effects of TMS arise not just from the FEF, but also from the dlPFC located on the gyral surface anterior of the FEF. Modeling studies have shown that TMS induces the largest electric fields at gyral crowns, with field strength dropping off progressively down a sulcus (Ravazzani et al., 1996; Thielscher et al., 2011). The FEF is mainly situated on the anterior bank of the arcuate sulcus, extending $\sim 8 \mathrm{~mm}$ below the cortical surface (Bruce and Goldberg, 1985). Hence it is unlikely that TMS selectively influenced the FEF without influencing the dlPFC. Further, saccadic and presaccadic profiles of activity can also be found on the gyral surface (Schall, 1991; Savaki et al., 2014), including FEF neurons located within $\sim 2-3$ $\mathrm{mm}$ of the cortical surface that project directly to the SC (Sommer and Wurtz, 2000). The dlPFC, located anterior to FEF and on the gyral surface, is also highly connected with the oculomotor system via the FEF, SC, or brainstem (Kuypers and Lawrence, 1967; Goldman and Nauta, 1976; Barbas and Pandya, 1989; Moschovakis et al., 2004; Hutchison and Everling, 2013), and anecdotal observations show that microstimulation rostral to the FEF, presumably within the dlPFC, evokes recruitment of the same contralateral head-turning synergy (Elsley et al., 2007). Importantly, a recent deactivation study showed that the dlPFC's influence on the SC is largely excitatory (Johnston et al., 2014), which is consistent with our proposal that TMS of the dlPFC can also initiate a polysynaptic response that culminates in neck muscle recruitment.

These studies reinforce the idea that those portions of the PFC that contribute to oculomotor activity are substantially larger than the FEF. Further, our results support previous human imaging studies (Petit and Beauchamp, 2003; Tark and Curtis, 2009) arguing for a broader role of the PFC in head orienting. Our results hearken back to Ferrier's work (Ferrier, 1874), which showed that surface electrical stimulation of the PFC in monkeys, albeit at very high levels, evoked an orienting response that consisted of multiple outputs, including saccades, head movements, and pupil dilation. Our work with TMS demonstrates its ability to selectively recruit head orienting, offering a metric that permits direct quantification.

Our interpretation hinges on the assumption that the evoked neck muscle responses originate directly from the PFC, rather than indirectly from M1 secondary to current spread. Importantly, TMS of the PFC consistently evoked a contralateral headturning synergy within $\sim 25 \mathrm{~ms}$, whereas TMS of M1 evoked bilateral neck muscle cocontraction within 5-10 ms followed by bilateral neck muscle suppression. The response to TMS of M1 may have originated from a direct corticospinal pathway (Lacroix et al., 2004; Montgomery et al., 2013) or a corticoreticular pathway (Fisher et al., 2012), and its timing is comparable to MEPs recorded on hand muscles in NHPs (Amaya et al., 2010). TMS to a similar location in humans evokes bilateral neck contraction within $\sim 10 \mathrm{~ms}$ (Thompson et al., 1997). Alternatively, the bilateral response could have arisen from the premotor cortex in the precentral gyrus from where whole-body defensive responses that include an ipsilateral head movement can be evoked (Graziano et al., 2002; Boulanger et al., 2009), although the timing and patterning of underlying neck muscle recruitment is unknown. Regardless, TMS during the memory-guided saccade task at such precentral locations near M1 did not produce state-dependent recruitment of the contralateral head-turning synergy, unlike TMS locations over the PFC. Overall, fundamental differences in the timing, synergy, and state dependency of neck muscle responses evoked by TMS of the PFC versus TMS of M1 implicate distinct descending motor pathways.

\section{The NHP oculomotor system as an animal model for the effects of TMS}

Our results fit in with a growing literature demonstrating the suitability of the NHP oculomotor system as an animal model for better linking the effects of TMS on brain and behavior (Gerits et al., 2011; Valero-Cabre et al., 2012; Mueller et al., 2014). As in the study by Valero-Cabre and colleagues (2012), our animals proved very capable of performing an oculomotor task during TMS application. This, along with a recent report describing techniques to overcome mechanical and electrical artifacts following TMS of the FEF (Mueller et al., 2014), potentiates the recording of neurophysiological activity following TMS during a behavioral task, both in the stimulated area and in interconnected oculomotor areas as well. While neurophysiological recordings in downstream locations have been performed following TMS of M1 in NHPs for some time (Baker et al., 1994; Fisher et al., 2012), the accumulated knowledge about the oculomotor system makes it an ideal platform to see how neural activity following TMS evolves in time throughout an interconnected network, how such activity depends on the level or phase of endogenous activity at the time of TMS (Thut et al., 2011), and how such induced changes are linked to behaviors. Our results demonstrate that neck EMG can provide a feedforward measure of oculomotor activation, reflecting the trial-by-trial efficacy of a TMS pulse in driving neural activity at a resolution that is not available through measures of saccadic behavior. In this regard, neck EMGs evoked by TMS of the PFC may provide a measure whose use can parallel the MEP, which is the de facto measurement of interest in many experiments involving TMS of the M1.

\section{References}

Amaya F, Paulus W, Treue S, Liebetanz D (2010) Transcranial magnetic stimulation and PAS-induced cortical neuroplasticity in the awake rhesus monkey. Clin Neurophysiol 121:2143-2151. CrossRef Medline 
Baker SN, Olivier E, Lemon RN (1994) Recording an identified pyramidal volley evoked by transcranial magnetic stimulation in a conscious macaque monkey. Exp Brain Res 99:529-532. Medline

Barbas H, Pandya DN (1989) Architecture and intrinsic connections of the prefrontal cortex in the rhesus monkey. J Comp Neurol 286:353-375. CrossRef Medline

Boulanger M, Bergeron A, Guitton D (2009) Ipsilateral head and centring eye movements evoked from monkey premotor cortex. Neuroreport 20: 669-673. CrossRef Medline

Brown P, Day BL, Rothwell JC, Thompson PD, Marsden CD (1991) Intrahemispheric and interhemispheric spread of cerebral cortical myoclonic activity and its relevance to epilepsy. Brain 114:2333-2351. CrossRef Medline

Bruce CJ, Goldberg ME (1985) Primate frontal eye fields. I. Single neurons discharging before saccades. J Neurophysiol 53:603-635. Medline

Castellote JM, Kumru H, Queralt A, Valls-Solé J (2007) A startle speeds up the execution of externally guided saccades. Exp Brain Res 177:129-136. CrossRef Medline

Cavanaugh J, Wurtz RH (2004) Subcortical modulation of attention counters change blindness. J Neurosci 24:11236-11243. CrossRef Medline

Chapman BB, Corneil BD (2014) Short-duration stimulation of the supplementary eye fields perturbs anti-saccade performance while potentiating contralateral head orienting. Eur J Neurosci 39:295-307. CrossRef Medline

Chapman BB, Pace MA, Cushing SL, Corneil BD (2012) Recruitment of a contralateral head turning synergy by stimulation of monkey supplementary eye fields. J Neurophysiol 107:1694-1710. CrossRef Medline

Corneil BD, Munoz DP (2014) Overt responses during covert orienting. Neuron 82:1230-1243. CrossRef Medline

Corneil BD, Olivier E, Richmond FJ, Loeb GE, Munoz DP (2001) Neck muscles in the rhesus monkey. II. Electromyographic patterns of activation underlying postures and movements. J Neurophysiol 86:1729-1749. Medline

Corneil BD, Olivier E, Munoz DP (2002) Neck muscle responses to stimulation of monkey superior colliculus. I. Topography and manipulation of stimulation parameters. J Neurophysiol 88:1980-1999. Medline

Corneil BD, Elsley JK, Nagy B, Cushing SL (2010) Motor output evoked by subsaccadic stimulation of primate frontal eye fields. Proc Natl Acad Sci U S A 107:6070-6075. CrossRef Medline

Dhamne SC, Kothare RS, Yu C, Hsieh TH, Anastasio EM, Oberman L, Pascual-Leone A, Rotenberg A (2014) A measure of acoustic noise generated from transcranial magnetic stimulation coils. Brain Stimul 7:432_ 434. CrossRef Medline

Edgley SA, Eyre JA, Lemon RN, Miller S (1997) Comparison of activation of corticospinal neurons and spinal motor neurons by magnetic and electrical transcranial stimulation in the lumbosacral cord of the anaesthetized monkey. Brain 120:839-853. CrossRef Medline

Elsley JK, Nagy B, Cushing SL, Corneil BD (2007) Widespread presaccadic recruitment of neck muscles by stimulation of the primate frontal eye fields. J Neurophysiol 98:1333-1354. CrossRef Medline

Ferrier D (1874) Experiments on the brain of monkeys. Proc R Soc Lond 23:409-432.

Fisher KM, Zaaimi B, Baker SN (2012) Reticular formation responses to magnetic brain stimulation of primary motor cortex. J Physiol 590:40454060. CrossRef Medline

Funahashi S, Bruce CJ, Goldman-Rakic PS (1990) Visuospatial coding in primate prefrontal neurons revealed by oculomotor paradigms. J Neurophysiol 63:814-831. Medline

Gerits A, Ruff CC, Guipponi O, Wenderoth N, Driver J, Vanduffel W (2011) Transcranial magnetic stimulation of macaque frontal eye fields decreases saccadic reaction time. Exp Brain Res 212:143-152. CrossRef Medline

Goldman PS, Nauta WJ (1976) Autoradiographic demonstration of a projection from prefrontal association cortex to the superior colliculus in the rhesus monkey. Brain Res 116:145-149. CrossRef Medline

Goonetilleke SC, Gribble PL, Mirsattari SM, Doherty TJ, Corneil BD (2011) Neck muscle responses evoked by transcranial magnetic stimulation of the human frontal eye fields. Eur J Neurosci 33:2155-2167. CrossRef Medline

Graziano MS, Taylor CS, Moore T (2002) Complex movements evoked by microstimulation of precentral cortex. Neuron 34:841-851. CrossRef Medline

Gu C, Stevens T, Thielscher A, Bell AH, Corneil BD (2013) Spatial and state-dependent effects of transcranial magnetic stimulation of the frontal eye fields in non-human primates. Soc Neurosci Abstr 39:365.06.21.

Hadjidimitrakis K, Moschovakis AK, Dalezios Y, Grantyn A (2007) Eye position modulates the electromyographic responses of neck muscles to electrical stimulation of the superior colliculus in the alert cat. Exp Brain Res 179:1-16. CrossRef Medline

Hallett M (2007) Transcranial magnetic stimulation: a primer. Neuron 55: 187-199. CrossRef Medline

Hutchison RM, Everling S (2013) Broad intrinsic functional connectivity boundaries of the macaque prefrontal cortex. Neuroimage 88C:202-211. CrossRef Medline

Ji RR, Schlaepfer TE, Aizenman CD, Epstein CM, Qiu D, Huang JC, Rupp F (1998) Repetitive transcranial magnetic stimulation activates specific regions in rat brain. Proc Natl Acad Sci U S A 95:15635-15640. CrossRef Medline

Johnston K, Everling S (2011) Frontal cortex and flexible control of saccades. In: The Oxford handbook of eye movements (Liversedge SP, Gilchrist I, Everling S, eds), pp 279-302. New York: Oxford UP.

Johnston K, Koval MJ, Lomber SG, Everling S (2014) Macaque dorsolateral prefrontal cortex does not suppress saccade-related activity in the superior colliculus. Cereb Cortex 24:1373-1388. CrossRef Medline

Kimiskidis VK, Papagiannopoulos S, Sotirakoglou K, Kazis DA, Kazis A, Mills KR (2005) Silent period to transcranial magnetic stimulation: construction and properties of stimulus-response curves in healthy volunteers. Exp Brain Res 163:21-31. CrossRef Medline

Kuypers HG, Lawrence DG (1967) Cortical projections to the red nucleus and the brain stem in the rhesus monkey. Brain Res 4:151-188. CrossRef Medline

Lacroix S, Havton LA, McKay H, Yang H, Brant A, Roberts J, Tuszynski MH (2004) Bilateral corticospinal projections arise from each motor cortex in the macaque monkey: a quantitative study. J Comp Neurol 473:147161. CrossRef Medline

Miniussi C, Harris JA, Ruzzoli M (2013) Modelling non-invasive brain stimulation in cognitive neuroscience. Neurosci Biobehav Rev 37:17021712. CrossRef Medline

Moliadze V, Zhao Y, Eysel U, Funke K (2003) Effect of transcranial magnetic stimulation on single-unit activity in the cat primary visual cortex. J Physiol 553:665-679. CrossRef Medline

Montgomery LR, Herbert WJ, Buford JA (2013) Recruitment of ipsilateral and contralateral upper limb muscles following stimulation of the cortical motor areas in the monkey. Exp Brain Res 230:153-164. CrossRef Medline

Moschovakis AK, Gregoriou GG, Ugolini G, Doldan M, Graf W, Guldin W, Hadjidimitrakis K, Savaki HE (2004) Oculomotor areas of the primate frontal lobes: a transneuronal transfer of rabies virus and $\left[{ }^{14} \mathrm{C}\right]-2$ deoxyglucose functional imaging study. J Neurosci 24:5726-5740. CrossRef Medline

Mueller JK, Grigsby EM, Prevosto V, Petraglia FW 3rd, Rao H, Deng ZD, Peterchev AV, Sommer MA, Egner T, Platt ML, Grill WM (2014) Simultaneous transcranial magnetic stimulation and single-neuron recording in alert non-human primates. Nat Neurosci 17:1130-1136. CrossRef Medline

Müri RM, Hess CW, Meienberg O (1991) Transcranial stimulation of the human frontal eye field by magnetic pulses. Exp Brain Res 86:219-223. Medline

Oude Nijhuis LB, Janssen L, Bloem BR, van Dijk JG, Gielen SC, Borm GF, Overeem S (2007) Choice reaction times for human head rotations are shortened by startling acoustic stimuli, irrespective of stimulus direction. J Physiol 584:97-109. CrossRef Medline

Pascual-Leone A, Walsh V, Rothwell J (2000) Transcranial magnetic stimulation in cognitive neuroscience-virtual lesion, chronometry, and functional connectivity. Curr Opin Neurobiol 10:232-237. CrossRef Medline

Petit L, Beauchamp MS (2003) Neural basis of visually guided head movements studied with fMRI. J Neurophysiol 89:2516-2527. CrossRef Medline

Ravazzani P, Ruohonen J, Grandori F, Tognola G (1996) Magnetic stimulation of the nervous system: induced electric field in unbounded, semiinfinite, spherical, and cylindrical media. Ann Biomed Eng 24:606-616. CrossRef Medline

Rezvani S, Corneil BD (2008) Recruitment of a head-turning synergy by low-frequency activity in the primate superior colliculus. J Neurophysiol 100:397-411. CrossRef Medline 
Salinas FS, Narayana S, Zhang W, Fox PT, Szabó CÁ (2013) Repetitive transcranial magnetic stimulation elicits rate-dependent brain network responses in non-human primates. Brain Stimul 6:777-787. CrossRef Medline

Savaki HE, Gregoriou GG, Bakola S, Moschovakis AK (2014) Topography of visuomotor parameters in the frontal and premotor eye fields. Cereb Cortex pii:bhu106. Medline

Schall JD (1991) Neuronal activity related to visually guided saccades in the frontal eye fields of rhesus monkeys: comparison with supplementary eye fields. J Neurophysiol 66:559-579. Medline

Siebner HR, Bergmann TO, Bestmann S, Massimini M, Johansen-Berg H, Mochizuki H, Bohning DE, Boorman ED, Groppa S, Miniussi C, PascualLeone A, Huber R, Taylor PC, Ilmoniemi RJ, De Gennaro L, Strafella AP, Kähkönen S, Klöppel S, Frisoni GB, George MS, et al. (2009) Consensus paper: combining transcranial stimulation with neuroimaging. Brain Stimul 2:58-80. CrossRef Medline

Siegmund GP, Inglis JT, Sanderson DJ (2001) Startle response of human neck muscles sculpted by readiness to perform ballistic head movements. J Physiol 535:289-300. CrossRef Medline

Silvanto J, Muggleton N, Walsh V (2008) State-dependency in brain stimulation studies of perception and cognition. Trends Cogn Sci 12:447-454. CrossRef Medline

Sommer MA, Wurtz RH (2000) Composition and topographic organization of signals sent from the frontal eye field to the superior colliculus. J Neurophysiol 83:1979-2001. Medline

Stuphorn V, Hoffmann KP, Miller LE (1999) Correlation of primate superior colliculus and reticular formation discharge with proximal limb muscle activity. J Neurophysiol 81:1978-1982. Medline

Tark KJ, Curtis CE (2009) Persistent neural activity in the human frontal cortex when maintaining space that is off the map. Nat Neurosci 12:14631468. CrossRef Medline

Tehovnik EJ, Lee K (1993) The dorsomedial frontal cortex of the rhesus monkey: topographic representation of saccades evoked by electrical stimulation. Exp Brain Res 96:430-442. Medline

Thielscher A, Opitz A, Windhoff M (2011) Impact of the gyral geometry on the electric field induced by transcranial magnetic stimulation. Neuroimage 54:234-243. CrossRef Medline

Thompson ML, Thickbroom GW, Mastaglia FL (1997) Corticomotor representation of the sternocleidomastoid muscle. Brain 120:245-255. CrossRef Medline

Thut G, Veniero D, Romei V, Miniussi C, Schyns P, Gross J (2011) Rhythmic TMS causes local entrainment of natural oscillatory signatures. Curr Biol 21:1176-1185. CrossRef Medline

Valero-Cabre A, Wattiez N, Monfort M, François C, Rivaud-Péchoux S, Gaymard B, Pouget P (2012) Frontal non-invasive neurostimulation modulates antisaccade preparation in non-human primates. PLoS ONE 7:e38674. CrossRef Medline

Werhahn KJ, Behrang-Nia M, Bott MC, Klimpe S (2007) Does the recruitment of excitation and inhibition in the motor cortex differ? J Clin Neurophysiol 24:419-423. CrossRef Medline

Wessel K, Kömpf D (1991) Transcranial magnetic brain stimulation: lack of oculomotor response. Exp Brain Res 86:216-218. Medline

Wipfli M, Felblinger J, Mosimann UP, Hess CW, Schlaepfer TE, Müri RM (2001) Double-pulse transcranial magnetic stimulation over the frontal eye field facilitates triggering of memory-guided saccades. Eur J Neurosci 14:571-575. CrossRef Medline

Xu-Wilson M, Tian J, Shadmehr R, Zee DS (2011) TMS perturbs saccade trajectories and unmasks an internal feedback controller for saccades. J Neurosci 31:11537-11546. CrossRef Medline 